\title{
Eccentric Digraph of Cocktail Party Graph and Hypercube
}

\author{
Tri Atmojo Kusmayadi and Nugroho Arif Sudibyo ${ }^{1}$
}

\begin{abstract}
Let $G$ be a graph with a set of vertices $V(G)$ and a set of edges $E(G)$. The distance from vertex $u$ to vertex $v$ in $G$, denoted by $d(u, v)$, is the length of the shortest path from vertex $u$ to $v$. The eccentricity of vertex $u$ in graph $G$ is the maximum distance from vertex $u$ to any other vertices in $G$, denoted by $e(u)$. Vertex $v$ is an eccentric vertex from $u$ if $d(u, v)$ $=\mathrm{e}(u)$. The eccentric digraph $\operatorname{ED}(G)$ of a graph $G$ is a graph that has the same set of vertices as $G$, and there is an arc (directed edge) joining vertex $u$ to $v$ if $v$ is an eccentric vertex from $u$. In this paper, we determine the eccentric digraph of a class of graph called the cocktail party graph and hypercube.
\end{abstract}

Keywords — cocktail party graph, eccentric digraph, eccentricity, hypercube

Abstrak-Misal $G$ adalah suatu graf dengan himpunan vertex $V(G)$ dan himpunan vertex $E(G)$. Jarak dari vertex u ke vertex $v$ di $G$, dinotasikan $d(u, v)$, adalah panjang dari path terpendek dari vertex $u$ ke v. Eksentrisitas vertex $u$ dalam graf $G$ adalah jarak maksimum dari vertex $u$ ke sebarang vertex yang lain di $G$, dinotasikan $e(u)$. Vertex vadalah suatu vertex eksentrik dari $u$ jika $d(u, v)=e(u)$. Digraf eksentrik $E D(G)$ dari suatu graf $G$ adalah suatu graf yang mempunyai himpunan vertex yang sama dengan himpunan vertex $G$, dan terdapat suatu arc (edge berarah) yang menghubungkan vertex $u$ ke $v$ jika $v$ adalah suatu vertex eksentrik dari u. Pada makalah ini, akan diselidiki digraph eksentrik dari suatu kelas graf yaitu graf cocktail party dan graf hypercube.

Kata Kunci-graf cocktail party, digraf eksentrik, eksentrisitas, hipercube

\section{INTRODUCTION}

$\mathrm{M}$ ost of the notations and terminologies follow that of [1-2]. Let $G$ be a graph with a set of vertices $\mathrm{V}(\mathrm{G})$ and a set of edges $\mathrm{E}(\mathrm{G})$. The distance from vertex $u$ to vertex $v$ in $\mathrm{G}$, denoted by $d(u, v)$, is the length of the shortest path from vertex $u$ to $v$. If there is no a path joining vertex $\mathrm{u}$ and vertex $\mathrm{v}$, then $d(u, v)=\infty$. The eccentricity of vertex $u$ in graph $G$ is the maximum distance from vertex $u$ to any other vertices in G, denoted by $e(u)$, and so $e(u)=\max \{\mathrm{d}(\mathrm{u}, \mathrm{v}) \mid \mathrm{v} \in \mathrm{V}(\mathrm{G})\}$. Radius of a graph $\mathrm{G}$, denoted by $\operatorname{rad}(\mathrm{G})$, is the minimum eccentricity of every vertex in G. The diameter of a graph $\mathrm{G}$, denoted by $\operatorname{diam}(\mathrm{G})$, is the maximum eccentricity of every vertex in G. If $e(u)=\operatorname{rad}(\mathrm{G})$, then vertex $\mathrm{u}$ is called central vertex. Center of a graph G, denoted by $\operatorname{cen}(\mathrm{G})$, is an induced subgraph formed from central vertices of G. Vertex $v$ is an eccentric vertex from $u$ if $d(u, v)=e(u)$. The eccentric digraph $\operatorname{ED}(G)$ of a graph $G$ is a graph that has the same set of vertices as $G, V(\operatorname{ED}(G))=V(G)$, and there is an arc (directed edge) joining vertex $u$ to $v$ if $v$ is an eccentric vertex from $u$. An arc of a digraph D joining vertex $u$ to $v$ and vertex $v$ to $u$ is called a symmetric arc. Further, Fred Buckley in [3] concluded that almost in every graph $G$, its eccentric digraph is $\operatorname{ED}(G)=\overline{\mathrm{G}}^{*}$, where $\overline{\mathrm{G}}^{*}$ is a complement of $\mathrm{G}$ which is every edge replaced by a symmetric arc.

One of the topics in graph theory is to determine the eccentric digraph of a given graph. The eccentric digraph of a graph was initially introduced by Fred Buckley [3]. Some authors have investigated the problem of finding the eccentric digraph. For example, [3] determined the eccentric digraph of a digraph, while [4] found the characterisation of the eccentric digraphs. [3] also

Tri Atmojo Kusmayadi and Nugroho Arif Sudibyo are with Department of Mathematics, FMIPA, Universitas Sebelas Maret, 57126, Surakarta, Indonesia. E-mail: trikusma@uns.ac.id, nugroho_su dibyo@yahoo.com. proposed an open problem to find the eccentric digraph of various classes of graphs. Some results related to this open problem can be found in [5-8].

In this paper, we also answer the open problem proposed by [3]. In particular, we determine the eccentric digraph of a graph called the cocktail party graph and hypercube.

\section{METHOD}

The materials of this research are mostly from the papers related to the eccentric digraph. There are three steps to determine the eccentric digraph from the given graph. The first step, we determined the distance from vertex $u$ to any vertex $v$ in the graph, denoted by $d(u, v)$, using Breadth First Search (BFS) Moore Algorithm taken from [1] as follows:

a. Take any vertex, say $u$, and labeled 0 which states the distance from $u$ to it self, and other vertices are labeled $\infty$

b. All vertices having label $\infty$ adjacent to $u$ are labeled by 1

c. All vertices having label $\infty$ adjacent to 1 are labeled by 2 and so on until the required vertex, say $v$, has already labeled.

The second step, we determined the vertex eccentricity $u$ by choosing the maximum distance from the vertex $u$, and so we obtained the eccentric vertex $v$ from $u$ if $d(u$, v) $=e(u)$.

The final step, by joining an arc from vertex $u$ to its eccentric vertex, so we obtained the eccentric digraph from the given graph.

\section{RESULTS AND DISCUSSION}

\section{A. Eccentric Diagraph of Cocktail Party Graph}

The cocktail party graph $H_{m, n}, m, n \geq 2$, as the graph with a vertex set $V=\left\{v_{1}, v_{2}, \ldots, v_{m n}\right\}$ partitioned into $n$ independent sets $V=\left\{I_{1}, \mathrm{I}_{2}, \ldots, v_{n}\right\}$ each of size $m$ such that $v_{i} v_{j} \in E$ for all $i, j \in\{1,2, \ldots, 2 n\}$ where $i \in I_{p}, j \in I_{q}, p \neq q$. 
The cocktail party graphs $H_{2,3}, H_{3,3}$, and $H_{3,4}$, can be described in Figure 1, Figure 2, and Figure 3, respectively [9].

\section{Lemma 1.}

Let $H_{m, n}$ be a cocktail party graph for $m, n \geq 2$, then the eccentricity of vertex $u_{i, j}, e\left(u_{i, j}\right)=2$, for $i=1,2 \ldots, m$ and $j=1,2, \ldots, n$.

\section{Proof.}

From Table 1, it is easy to see that the farthest distance from vertex $u_{i j}$ to vertex $u_{i k}$ is 2 , for $j \neq k$, so the eccentricity of $u_{i j}, e\left(u_{i, j}\right)$, is 2 .

\section{Lemma 2.}

Let $H_{m, n}$ be a cocktail party graph for $m, n \geq 2$, then the eccentric vertex of vertex $u_{i, j}$ is $u_{i, k}$, for $i=1,2 \ldots, m$ and $j=1,2, \ldots, n$.

\section{Proof.}

By Lemma 1, the eccentricity of $u_{i j}$ is 2 , so the eccentric vertex $u_{i, j}$ is vertex $u_{i k}$, for $j \neq k, i=1,2 \ldots, m, j, k=1,2, \ldots, n$.

\section{Lemma 3.}

Let $H_{m, n}$ be a cocktail party graph for $m, n \geq 2$, then its eccentric digraph has the vertex set

$V\left(H_{m, n}\right)=\left\{u_{11}, u_{12}, \ldots, u_{n m}\right\}$

and the arc set

$A\left(E D\left(H_{m, n}\right)\right)=\left\{\overleftrightarrow{u_{i j} u_{i k}} / i=1,2, \ldots, m, j=1,2, \ldots, n\right.$,

$j \neq k, k=1,2, \ldots, n\}$.

where $\operatorname{arcs} \overleftrightarrow{\mathrm{u}_{\mathrm{ij}} \mathrm{u}_{\mathrm{ik}}}, \mathrm{i}=1,2, \ldots, \mathrm{m}, \mathrm{j}=1,2, \ldots, \mathrm{n}, \mathrm{k}=1,2, \ldots, \mathrm{n}$, $\mathrm{j} \neq \mathrm{k}$, are symmetric arcs.

\section{Proof.}

The arcs can be obtained by joining every vertex to its eccentric vertex of a cocktail party graph $H_{m, n}$. By Lemma 2, the eccentric vertex of vertex $u_{i j}$ is vertex $u_{i k}$ for $j \neq k$, so $u_{i j}$ is joined to $u_{i k}$ forming a symmetric arc $\overleftrightarrow{u_{i j} u_{i k}}$. Hence, the eccentric digraph of $H_{m, n}$ has the vertex set $V\left(E D\left(H_{m, n}\right)\right)=V\left(H_{m, n}\right)$ and the $\operatorname{arcset} A\left(E D\left(H_{m, n}\right)\right)$.

\section{Theorem 4}

Let $H_{m, n}$ be a cocktail party graph for $m, n \geq 2$, then the eccentric digraph of $H_{m, n}$,

$E D\left(H_{m, n}\right)$ is a digraph $n K_{m}$ having the vertex set

$V\left(H_{m, n}\right)=\left\{u_{11}, u_{12}, \ldots, u_{n m}\right\}$

and the arc set

$$
\begin{aligned}
& A\left(E D\left(H_{m, n}\right)\right)=\left\{\overleftrightarrow{u_{i j} u_{i k}} / i=1,2, \ldots, m, j=1,2, \ldots, n,\right. \\
& j \neq k, k=1,2, \ldots, n\} .
\end{aligned}
$$

\section{Proof.}

By Lemma 3, the arc from vertex $u_{i j}$ to vertex $u_{i k}$, for $j \neq k$, are symmetric. So, the obtained digraph is a digraph $n K_{m}$ having the vertex set $V\left(E D\left(H_{m, n}\right)\right)$ and the arc set $A\left(E D\left(H_{m, n}\right)\right)$. This completes the proof of the theorem. The eccentric digraphs of cocktail party graphs $H_{2,3}, H_{3,3}$, and $H_{3,4}$ are shown in the Figure 4, 5, and 6, respectively.

\section{B. Eccentric Diagraph of Hypercupe}

The hypercube $Q_{n}$ is the graph whose vertex set is $\{0,1\}^{\mathrm{n}}$ and where two vertices are adjacent if they differ in exactly one coordinate. Let $\mathrm{V}\left(\mathrm{Q}_{\mathrm{n}}\right)=\left\{\mathrm{v}_{1}, \mathrm{v}_{2}, \ldots ., \mathrm{v}_{2^{\mathrm{n}}}\right\}$ and let $v_{i} \in V\left(Q_{n}\right)$ with $v_{\mathrm{i}}=\left(v_{i 1}, v_{i 2}, \ldots, v_{i n}\right), v_{i j}=0$ or 1 . Then $\bar{v}_{i}=\left(\bar{v}_{i 1}, \bar{v}_{i 2}, \ldots, \bar{v}_{i n}\right)$ is a vertex of $V\left(Q_{n}\right)$ with $\bar{v}_{i j} \neq v_{i j}, i, j=0$ or 1 [2]. The hypercube $Q_{1}, Q_{2}$, and $Q_{3}$ can be described in Figure 7, Figure 8 and Figure 9, respectively.

Theorem 5. Let $Q_{\mathrm{n}}$ be a hypercube for $n \geq 2$, then the eccentric digraph of $Q_{\mathrm{n}}, E D\left(Q_{\mathrm{n}}\right)$ is a digraph $2^{n-1} K_{2}$ having vertex set $V\left(Q_{n}\right)=\left\{\begin{array}{lll}V_{l}, & V_{2}, \ldots ., V_{2}{ }^{n}\end{array}\right\}$ and the arc $\operatorname{set} A\left(E D\left(Q_{n}\right)\right)=\overleftrightarrow{v_{i} \overrightarrow{v_{i}}}, i=1,2, \ldots, 2^{n-1}$ where, arc $\overleftrightarrow{v_{i} \vec{v}_{i}}, i=1,2, \ldots, 2^{n-1}$, are symmetric arcs

Proof. From Table 2, it is easy to see that the farthest distance between any two vertices of hypercube $Q_{n}$ is $n$. In addition, the arcs are from vertex $\mathrm{v}_{\mathrm{i}}$ to vertex $\overline{\mathrm{vi}}$ for every $i=1,2, \ldots, 2^{n-1}$, and all of the arcs are symmetric. Based on the observation, it can be obtained that the eccentric digraph of $E D\left(Q_{1}\right)$ is a digraph $K_{2}, E D\left(Q_{2}\right)$ is a digraph $2 K_{2}, E D\left(Q_{3}\right)$ is a digraph $4 K_{2}$, and $E D\left(Q_{4}\right)$ is a digraph $8 K_{2}$. Hence, the eccentric digraph of $Q_{n}$ is a digraph $2^{\text {n-1 }} K_{2}$. So, the obtained digraph is a digraph having the vertex set $V\left(Q_{n}\right)$ and the arc set $A\left(E D\left(Q_{n}\right)\right)$. This completes the proof of the theorem. The eccentric digraphs of cocktail party graphs $Q_{1}, Q_{2}$ and $Q_{3}$ are shown in the Figure 10, Figure 11, and Figure 12, respectively.

\section{CONCLUSION}

The results show that the eccentric digraph $E D\left(H_{m, n}\right)$ of a cocktail party graph $H_{m, n}$ for $m, n \geq 2$, is a digraph $n K_{m}$ having the vertex set $\mathrm{V}\left(\mathrm{H}_{m n}\right)=\left\{u_{11}, u_{12}, \ldots . ., u_{n m}\right\}$ and the arc set $A\left(E D\left(H_{m}, n\right)\right)=\left\{u_{i j} u_{i k} / i-1,2, \ldots, m j-1,2, \ldots, n\right.$ $j \neq k, k=1,2, \ldots, n\}$ and the eccentric digraph $\operatorname{ED}\left(Q_{n}\right)$ of a hypercube graph $Q_{n}$ is a digraph $2^{n-1} K_{2}$ having the vertex set $V\left(Q_{\mathrm{n}}\right)=\left\{\mathrm{v}_{1}, \mathrm{v}_{2}, \ldots, \mathrm{v}_{2}{ }^{\mathrm{n}}\right\}$ and the $\operatorname{arc} \operatorname{set} A\left(E D\left(Q_{n}\right)\right)$ $=v_{i} v_{i}, i=1,2, \ldots, 2^{n-1}$.

As mentioned in previous sections the main goal of this paper is to find the eccentric digraph of a given class of graph. Some authors have conducted research on this problem. Most of them have left some open problems on their paper for the future research. We suggest readers to investigate the problem proposed by [3] by considering other classes of graphs.

\section{ACKNOWLEDGEMENT}

The authors would like to thank to Department of Mathematics Faculty of Mathematics and Natural Sciences Universitas Sebelas Maret for supporting this research. 


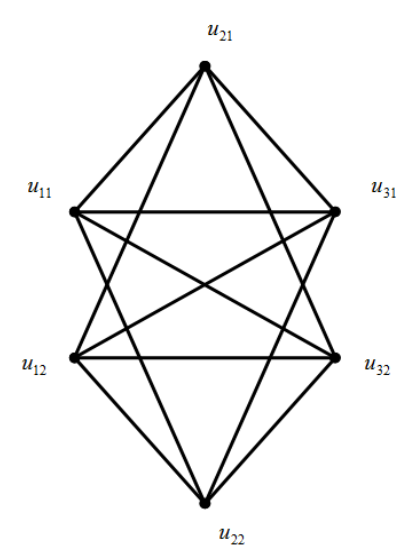

Figure 1 . The cocktail party graph $H_{2,3}$

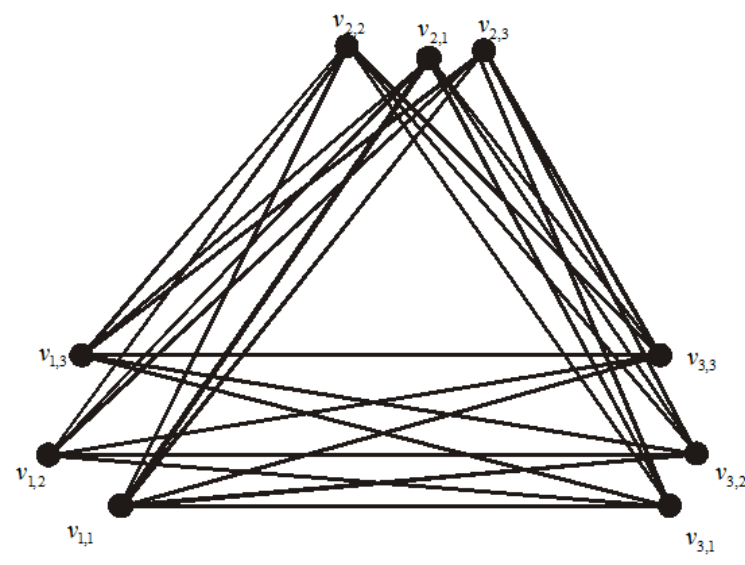

Figure 2. The cocktail party graph $H_{3,3}$

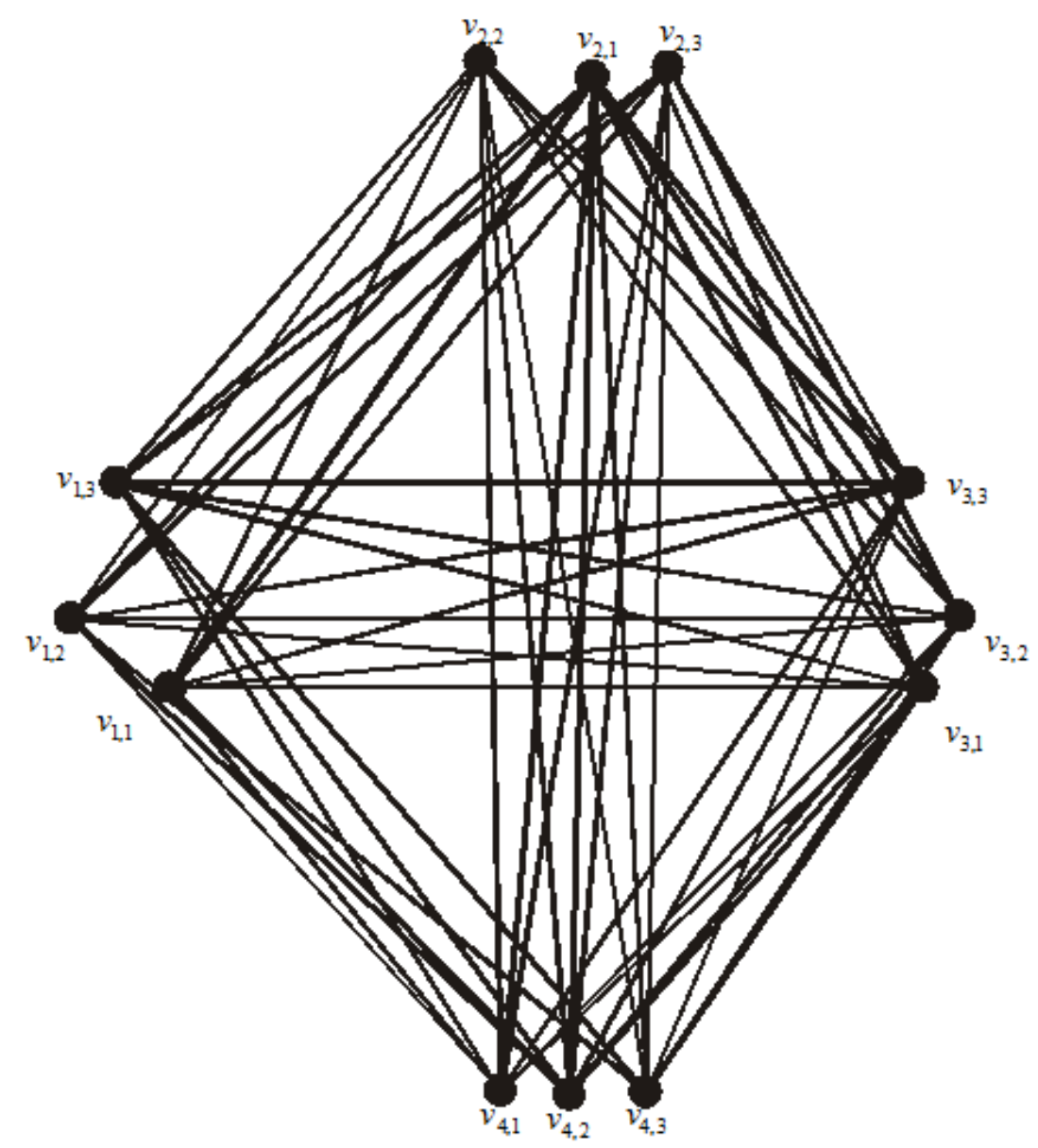

Figure 3 . The cocktail party graph $H_{3,4}$ 


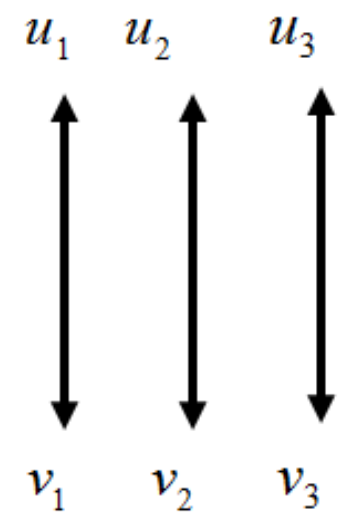

Figure 4. The eccentric digraph of cocktail party graph $H_{2,3}$
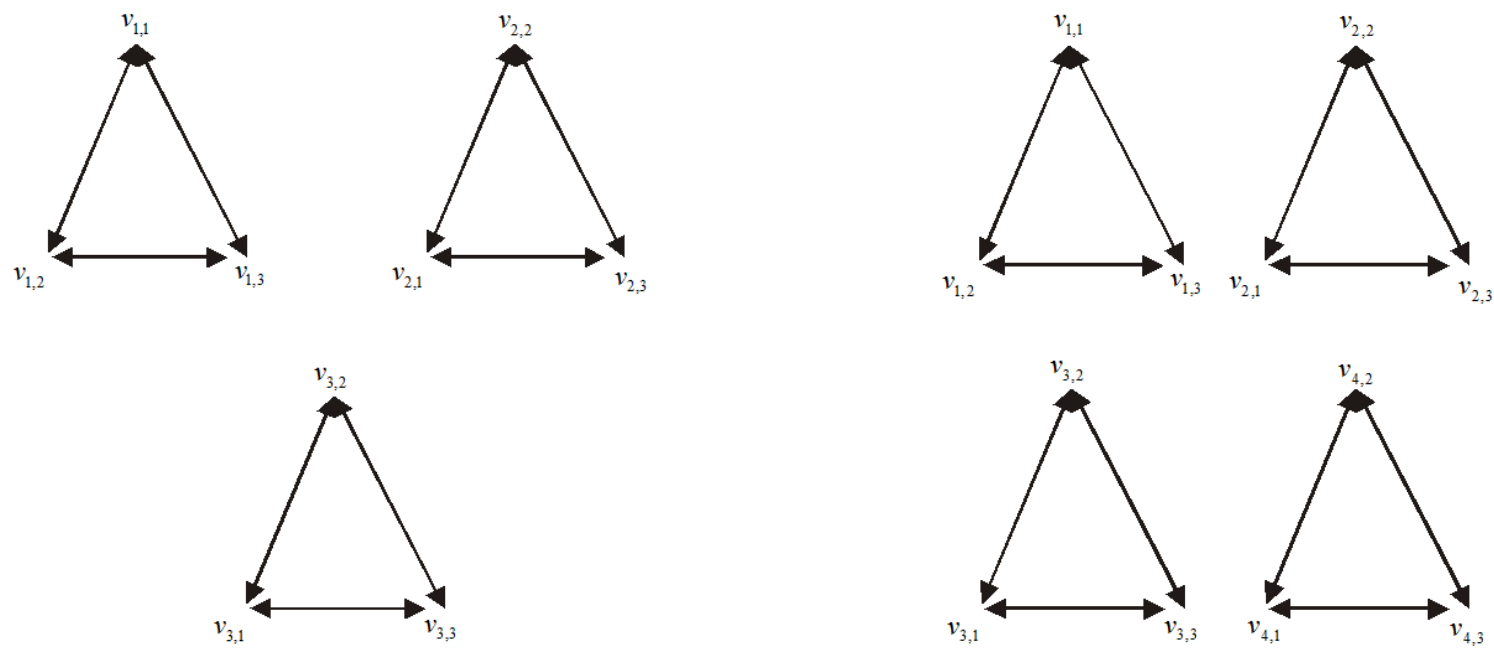

Figure 5. The eccentric digraph of cocktail party graph $H_{3,3}$

Figure 6 . The eccentric digraph of cocktail party graph $H_{3,4}$

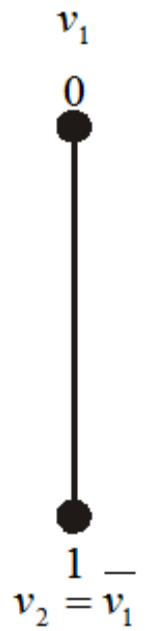

Figure 7. The hypercube graph $Q_{l}$ 


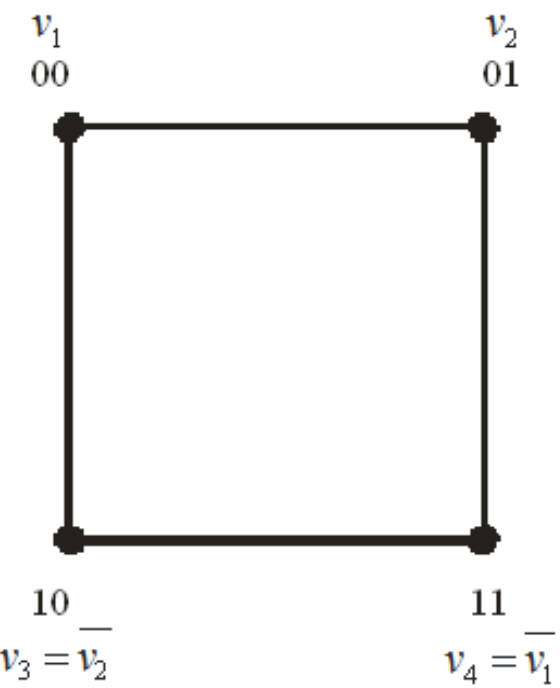

Figure 8. The hypercube graph $Q_{2}$

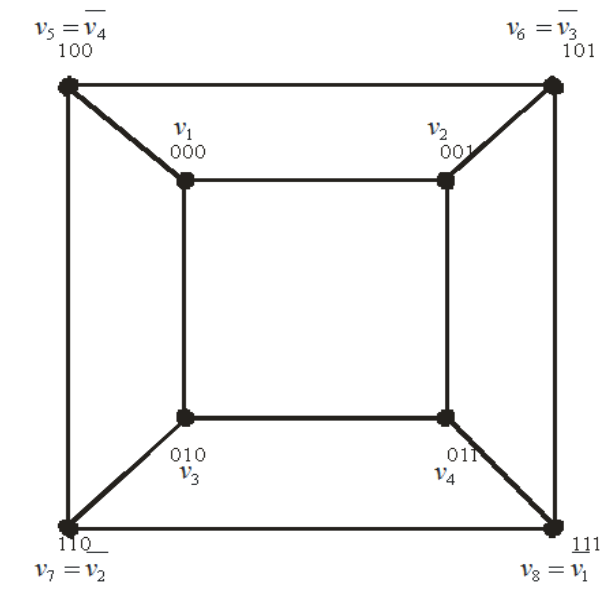

Figure 9. The hypercube graph $Q_{3}$ $v_{2}$

$v_{4}=\overline{v_{1}}$

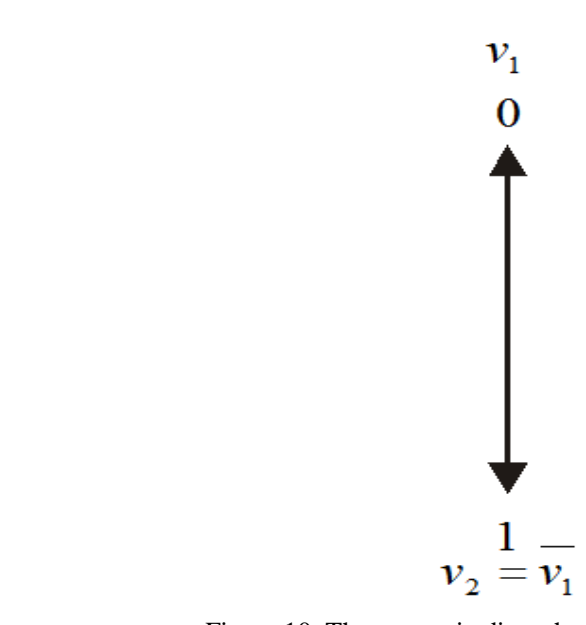

Figure 10. The eccentric digraph of hypercube graph $Q_{l}$

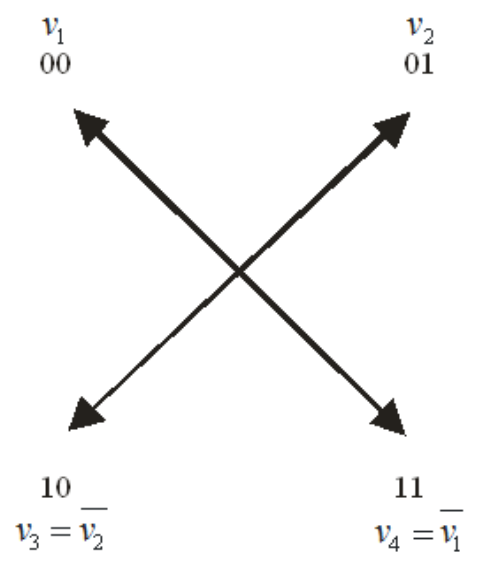

Figure 11. The eccentric digraph of hypercube graph 


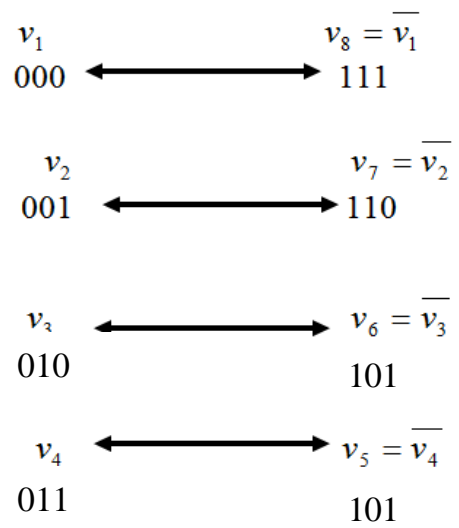

Figure 12. The eccentric digraph of hypercube graph $Q_{3}$

TABLE 1.

DistANCE BETWEen ANy Two VESICLE OF COCKTAIL PARTy GRAPH $H_{M, N}$

\begin{tabular}{|c|c|c|c|c|c|c|c|c|c|c|}
\hline vertex & $\mathrm{v}_{1,1}$, & $\ldots$ & $\mathrm{v}_{1, \mathrm{n}}$ & $\mathrm{v}_{2,1}$, & $\ldots$ & $\mathrm{v}_{2, \mathrm{n}}$ & $\ldots$ & $\mathrm{v}_{\mathrm{m}, 1}$ & $\ldots$ & $\mathrm{V}_{\mathrm{m}, \mathrm{n}}$ \\
\hline $\mathrm{v}_{1,1}$ & 0 & $\ldots$ & 2 & 1 & $\ldots$ & 1 & $\ldots$ & 1 & $\ldots$ & 1 \\
\hline . & . & . & . & . & . & . & . & . & . & . \\
\hline . & . & . & . & . & . & . & . & . & . & . \\
\hline . & . & . & . & . & . & . & . & . & . & . \\
\hline $\mathrm{v}_{1, \mathrm{n}}$ & 2 & $\ldots$ & 0 & 1 & $\ldots$ & 1 & $\ldots$ & 1 & $\ldots$ & 1 \\
\hline $\mathrm{v}_{2,1}$ & 1 & $\ldots$ & 1 & 0 & $\ldots$ & 2 & $\ldots$ & 1 & $\ldots$ & 1 \\
\hline . & . & . & . & . & . & . & . & . & . & . \\
\hline . & . & $\cdot$ & . & . & . & . & . & . & . & . \\
\hline . & . & . & . & . & . & . & . & . & . & . \\
\hline $\mathrm{v}_{2, \mathrm{n}}$ & 1 & $\ldots$ & 1 & 2 & $\ldots$ & 0 & $\ldots$ & 1 & $\ldots$ & 1 \\
\hline . & . & . & . & . & . & . & . & . & . & . \\
\hline . & . & . & . & . & . & . & . & . & . & . \\
\hline . & . & $\cdot$ & . & . & . & . & . & . & . & . \\
\hline $\mathrm{v}_{\mathrm{m}, 1}$ & 1 & $\ldots$ & 1 & 1 & $\ldots$ & 1 & $\ldots$ & 0 & $\ldots$ & 2 \\
\hline . & . & . & . & . & . & . & . & . & . & . \\
\hline . & . & . & . & . & . & . & . & . & . & . \\
\hline . & . & $\cdot$ & . & . & . & . & . & . & . & . \\
\hline $\mathrm{V}_{\mathrm{m}, \mathrm{n}}$ & 1 & $\ldots$ & 1 & 1 & $\ldots$ & 1 & $\ldots$ & 2 & $\ldots$ & 0 \\
\hline
\end{tabular}

TABLE 2.

DisTANCE BETWEEN ANY TWO VESICLE OF GRAPH QN

\begin{tabular}{ccccc}
\hline vertex & $v_{1}$ & $v_{2}$ & $\ldots$ & $v_{2}{ }^{\mathrm{n}}$ \\
\hline$v_{1}$ & 0 & 1 & $\ldots$ & $n-1$ \\
$v_{2}$ & 1 & 0 & $\ldots$ & $\ldots$ \\
$\cdot$ & & & & \\
$\cdot$ & $\cdot$ & $\cdot$ & $\ldots$ & $\ldots$ \\
$\cdot$ & $\cdot$ & $\cdot$ & $\ldots$ & \\
$v_{2}{ }^{\mathrm{n}}$ & $\cdot$ & $\cdot$ & $\ldots$ & 0 \\
\hline
\end{tabular}




\section{REFERENCES}

[1] G. Chartand and O. R. Oellermann, Applied and Algorithmic Graph Theory, International Series in Pure and Applied Mathematics, Mc. Graw-Hill Inc., California, 1993.

[2] J. A. Gallian, Dynamic Survey of Graph Labeling, The Electronic Journal of Combinatorics, p.17, 2011.

[3] J. Boland and M. Miller, "The Eccentric Digraph of a Digraph", in Proceeding of AWOCA'01, LembangBandung, Indonesia, 2001.

[4] J. Gimbert, N. Lopez, M. Miller, and J. Ryan, Characterization of Eccentric Digraphs, Discrete Mathematics, vol.306, issue 2, pp. 210 - 219, 2006.

[5] T. A. Kusmayadi and M. Rivai, "The Eccentric Digraph of an Umbrella Graph", in Proceeding of INDOMS International Conference on Mathematics and Its Applications (IICMA), Gadjah Mada University Yogyakarta, Indonesia, pp. 0627-0638, 2009a
[6] T. A. Kusmayadi and M. Rivai, "The Eccentric Digraph of a Double Cones Graph", in Proceeding of INDOMS International International Conference on Mathematics and Its Applications (IICMA), Gadjah Mada University Yogyakarta, Indonesia, 2009b.

[7] T. A. Kusmayadi and M. Mulyono, "The Eccentric Digraph of a Friendship Graph", Proceeding of The Third International Conference on Mathematics and Natural Sciences (ICMNS), Institut Teknologi Bandung, Indonesia, pp. 1111-1122, 2010.

[8] T. A. Kusmayadi and Y. U. Pratama, "The Eccentric Digraph of a Firecracker Graph", Proceeding of The International Conference on Numerical Optimization (ICeMath2011), Universitas Ahmad Dahlan, no.2-1 - no.27, 2011.

[9] M. Sutton and M. Miller, "Mod sum graph labelling of $\mathrm{H}_{\mathrm{mn}}$ and $\mathrm{K}_{\mathrm{n}}$," Australas. Journal of Combinatorics, no.20, pp. 233-240, 1999. 